\title{
Solutions of Linear and Nonlinear Volterra Integral Equations Using Hermite and Chebyshev Polynomials
}

\author{
Md. Shafiqul Islam ${ }^{1^{*}}$ Md. Azizur Rahman ${ }^{2}$ \\ ${ }^{1}$ Department of Mathematics, University of Dhaka, Dhaka - 1000, Bangladesh \\ *Corresponding author and email: mdshafiqul_mat@du.ac.bd \\ ${ }^{2}$ Department of Mathematics \& Statistics, Bangladesh University of Business \& Technology, \\ Dhaka - 1216, Bangladesh \\ Email: mdazizur201171@gmail.com
}

\section{ABSTRACT}

The purpose of this work is to provide a novel numerical approach for the Volterra integral equations based on Galerkin weighted residual approximation. In this method Hermite and Chebyshev piecewise, continuous and differentiable polynomials are exploited as basis functions. A rigorous effective matrix formulation is proposed to solve the linear and nonlinear Volterra integral equations of the first and second kind with regular and singular kernels. The algorithm is simple and can be coded easily. The efficiency of the proposed method is tested on several numerical examples to get the desired and reliable good accuracy.

\section{Keywords}

Linear and nonlinear Volterra integral equations; Galerkin method; Hermite and Chebyshev polynomials.

\section{Academic Discipline and Sub-Disciplines}

Mathematics, Numerical Analysis

\section{TYPE (METHOD/APPROACH)}

\section{Research Paper}

\section{Council for Innovative Research}

Peer Review Research Publishing System

\author{
Journal: INTERNATIONAL JOURNAL OF COMPUTERS \& TECHNOLOGY \\ Vol 11, No.8 \\ editor@cirworld.com \\ www.cirworld.com, member.cirworld.com
}




\section{INTRODUCTION}

Most mathematical models used in many applied problems of physics, biology, chemistry, engineering, and in other areas are transformed into integral equations, namely linear and nonlinear Volterra integral equations of the first or second kind. For this, many authors have paid attention to the study of these equations from the viewpoint of their theoretical properties, numerical treatment, as well as its applications. Consequently, various techniques [1, 2] have been presented for solving Volterra integral equations such as Adomian's decomposition method, series solution method, Laplace transform method and successive substitution method. These methods generally cover the analytic closed form solution of such equations. But many of the equations that govern the physical problems have no solution in closed form. Therefore, to find the solutions of such problems, we must resort to solving these equations numerically.

Since piecewise polynomials are incredibly useful mathematical tools as they are simply defined, can be calculated quickly on computer systems and represent a tremendous variety of functions. They can be differentiated and integrated easily, and can be pieced together to form spline curves that can approximate any function to any accuracy desired. As a result, many numerical methods have been developed for solving differential and integral equations by many researchers using various piecewise polynomials in recent years. Bellour and Rawashdeh [3] used Taylor polynomials method to solve only first kind integral equations while a recursive scheme [4] were used by Maleknejad et al for the solutions of such type of problems. Also Shahsavaran [5 - 8] solved first and second kind linear and nonlinear Volterra integral equations by collocation method while spectral method has been used by Chen and Tang [9]. Maleknejad et al [10] used Chebyshev polynomials for numerical solution of nonlinear integral equations. On the other hand, Jafari et al [11] used Legendre wavelets for the solution of system of linear integral equations. Bernstein polynomials have been used by Bhattacharya and Mandal [12] to find out the solutions of Volterra integral equations of first and second kind. These polynomials further used to investigate the solution of such problems by Maleknejad et al [13]. Berenguer et al [14] proposed analytical techniques for numerical solutions of the second kind Volterra integral equations while Kamyad et al [15] solved linear and nonlinear equations and Babolian et al [16] studied on nonlinear Volterra-Fredholm Integral and Integro-Differential Equations. But none has attempted, to the knowledge of the present authors, using Hermite polynomials to solve the Volterra integral equations.

However, in this paper, we provide a numerical approach for the Volterra integral equations based on Hermite and Chebyshev piecewise polynomials [17] basis by the technique of Galerkin weighted residual method [18]. Firstly, we give an introduction of Hermite and Chebyshev piecewise polynomials. Then, we drive a matrix formulation for general linear problems by the technique of Galerkin method while nonlinear case is given through numerical examples.

\section{HERMITE POLYNOMIALS}

Hermite polynomial, named after a French mathematician Charles Hermite (1822-1901), is a family of polynomial functions, which is the solution of a special case of differential equation in the treatment of harmonic oscillator in quantum mechanics. The general form of the Hermite polynomials [17] of nth degree is defined by

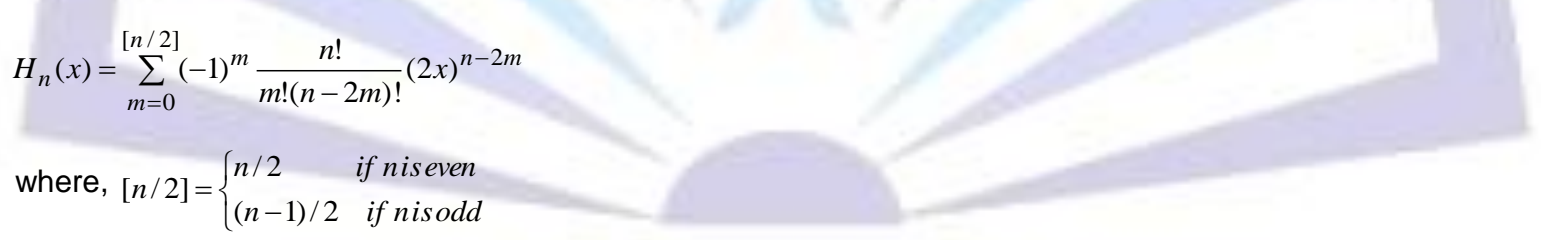

The first few Hermite polynomials from the equation (1) are given below:

$$
\begin{aligned}
& H_{0}(x)=1, H_{1}(x)=2 x, H_{2}(x)=4 x^{2}-2, H_{3}(x)=8 x^{3}-12 x, H_{4}(x)=16 x^{4}-48 x^{2}+12, \\
& H_{5}(x)=32 x^{5}-160 x^{3}+120 x, \quad H_{6}(x)=64 x^{6}-480 x^{4}+720 x^{2}-120
\end{aligned}
$$

\section{CHEBYSHEV POLYNOMIALS}

The Chebyshev polynomials, named after Pafnuty Chebyshev, are a sequence of orthogonal polynomials which are related to de Moivre's formula and which can be defined recursively. The general form of the Chebyshev polynomials [17] of nth degree is defined by 


$$
T_{n}(x)=\sum_{m=0}^{[n / 2]}(-1)^{m} \frac{n !}{(2 m) !(n-2 m) !}\left(1-x^{2}\right)^{m} x^{n-2 m}
$$

where, $[n / 2]= \begin{cases}n / 2 & \text { if } n \text { is even } \\ (n+1) / 2 & \text { if } n \text { is odd }\end{cases}$

The first few Chebyshev polynomials from the equation (2) are given below :

$$
\begin{gathered}
T_{0}(x)=1, T_{1}(x)=x, T_{2}(x)=2 x^{2}-1, T_{3}(x)=4 x^{3}-3 x, T_{4}(x)=8 x^{4}-8 x^{2}+1, T_{5}(x)=16 x^{5}-20 x^{3}+5 x, \\
T_{6}(x)=32 x^{6}-48 x^{4}+18 x^{2}-1
\end{gathered}
$$

Now the first six Hermite polynomials over the interval $[-1,1]$ are shown in Fig. 1(a), and the first six Chebyshev polynomials are shown in Fig. 1(b).

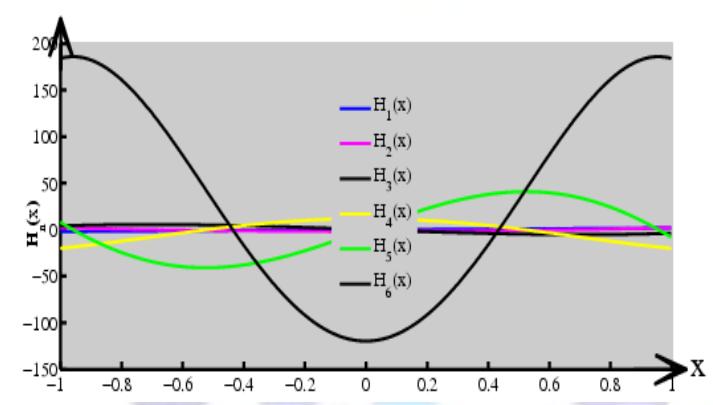

Fig. 1(a). Graph of first 6 Hermite polynomials over the interval $[-1,1]$

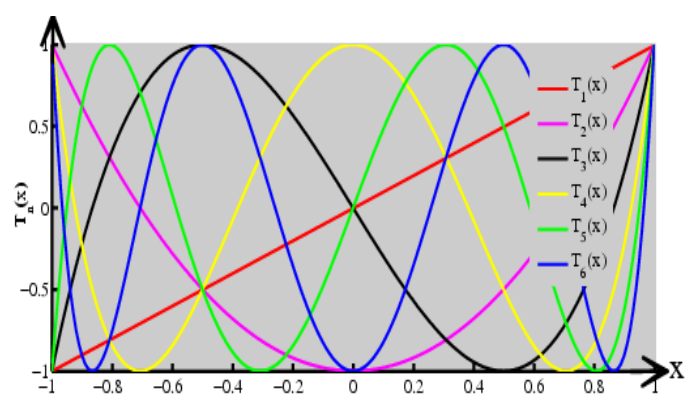

Fig. 1(b). Graph of first 6 Chebyshev polynomials over the interval $[-1,1]$

\section{MATHEMATICAL FORMULATION OF INTEGRAL EQUATIONS}

In this section, first we consider the Volterra integral equation (VIE) of the first kind [1, 2], given by

$$
\int_{a}^{x} k(x, t) u(t) d t=f(x), \quad a \leq x \leq b
$$

where $u(x)$ is the unknown function, to be determined, $k(x, t)$ is the kernel function, continuous or discontinuous and $f(x)$ being the known function satisfying $f(a)=0$.

Now we use the technique of Galerkin method, [Lewis, 14], to find an approximate solution $\tilde{u}(x)$ of $(3)$. For this, we assume that

$$
\tilde{u}(x)=\sum_{i=0}^{n} c_{i} N_{i}(x)
$$

where $N_{i}(x)$ are Hermite or Chebyshev polynomials of degree $i$ defined in equation (1-2), $c_{i}$ are unknown parameters, to be determined and $n$ is the number of piecewise polynomials. An approximate solution $\tilde{u}(x)$ will not produce an identically zero function but a function called the residual function. Substituting (4) into (3), we get the residual function as

$$
R(x)=\sum_{i=0}^{n} c_{i} \int_{a}^{x} k(x, t) N_{i}(t) d t-f(x), a \leq x \leq b
$$

Now the Galerkin equations of (3) corresponding to the approximation (4), given by 


$$
\int_{a}^{b} R(x) N_{j}(x) d x=0
$$

Using (5) and (6) after minor simplification, we obtain

$$
\sum_{i=0}^{n} c_{i} \int_{a}^{b}\left[\int_{a}^{x} k(x, t) N_{i}(t) d t\right] N_{j}(x) d x=\int_{a}^{b} N_{j}(x) f(x) d x, j=0,1, \ldots \ldots, n
$$

The above equations (7) are equivalent to the matrix form

$$
D C=B
$$

where the elements of the matrix $C, D$ and $B$ are $c_{i}, d_{i, j}$ and $b_{j}$, respectively, given by

$$
\begin{aligned}
& c_{i}=\left[c_{1}, c_{2}, c_{3}, \ldots \ldots \ldots \ldots c_{n}\right]^{T} \\
& d_{i, j}=\int_{a}^{b}\left[\int_{a}^{x} k(x, t) N_{i}(t) d t\right] N_{j}(x) d x, i, j=0,1, \ldots \ldots, n \\
& b_{j}=\int_{a}^{b} N_{j}(x) f(x) d x, j=0,1, \ldots \ldots, n
\end{aligned}
$$

Now the unknown parameters $c_{i}$ are determined by solving the system of equations (9) and substituting these values of parameters in (4), we get the approximate solution $\tilde{u}(x)$ of the integral equation (3).

Now, we consider the Volterra integral equation (VIE) of the second kind [1, 2] given by

$$
u(x)+\lambda \int_{a}^{x} k(x, t) u(t) d t=f(x), \quad a \leq x \leq b
$$

where $u(x)$, is the unknown function to be determined, $k(x, t)$ is the kernel function, continuous or discontinuous, $f(x)$ being the known function and $\lambda$ is the constant. Then applying the same procedure as described above, we obtain the matrix form

$$
D C=B
$$

where the elements of the matrix $C, D$ and $B$ are $c_{i}, d_{i, j}$ and $b_{j}$, respectively, given by

$$
\begin{aligned}
& c_{i}=\left[c_{1}, c_{2}, c_{3}, \ldots \ldots \ldots \ldots c_{n}\right]^{T} \\
& d_{i, j}=\left[\int_{a}^{b}\left[N_{i}(x)+\lambda \int_{a}^{x} k(x, t) N_{i}(t) d t\right] N_{j}(x) d x\right], i, j=0,1, \ldots \ldots, n \\
& b_{j}=\int_{a}^{b} N_{j}(x) f(x) d x, j=0,1, \ldots \ldots, n
\end{aligned}
$$

Now the unknown parameters $c_{i}$ are determined by solving the system of equations (12) and substituting these values of parameters in (4), we get the approximate solution $\tilde{u}(x)$ of the integral equation (10). The absolute error for this formulation is defined by

$$
\text { Absolute Error }=|u(x)-\tilde{u}(x)|
$$

The formulation for nonlinear integral equation will be discussed by considering numerical problems in the next section. 


\section{NUMERICAL EXAMPLES}

To verify the proposed method, we consider some linear and nonlinear Volterra integral equations with regular and weakly singular kernels, because the exact solutions for these problems are available in the literature. For all the examples, the solutions obtained by the proposed method and are thus compared with the exact solutions using two piecewise polynomials, namely, Hermite and Chebyshev polynomials. The convergence of each linear Volterra integral equations is calculated by

$$
E=\left|\tilde{u}_{n+1}(x)-\tilde{u}_{n}(x)\right|<\delta
$$

where $\tilde{u}_{n}(x)$ denotes the approximate solution by the proposed method using nth degree polynomial approximation and $\delta$ varies from $10^{-7}$ (Hermite polynomials) and $10^{-6}$ (Chebyshev polynomials) for $n \geq 10$.

Example 1: Consider the LVIE of first kind with continuous kernels [2, pp 43]

$$
\int_{0}^{x}(5+3 x-3 t) u(t) d t=5 x^{2}+x^{3}, \quad 0 \leq x \leq 1
$$

The exact solution is $u(x)=2 x$. Using Hermite and Chebyshev polynomials and the formula derived in the equation (8) for $n \geq 1$, we get the approximate solution is $\tilde{u}(x)=2 x$, which is the exact solution.

Example 2: Consider the LVIE of second kind with continuous kernels [14]

$$
u(x)-\int_{0}^{x} t x u(t) d t=x^{5}-\frac{x^{8}}{7}, 0 \leq x \leq 1
$$

The exact solution is $u(x)=x^{5}$. Using Hermite and Chebyshev polynomials and the formula derived in the equation (11) for $n \geq 5$, we get the approximate solution is $\tilde{u}(x)=x^{5}$, which coincides with the exact solution. On the other hand, the absolute errors were obtained in the order upto $10^{-5}$ for $n=65$ (number of Biorthogonal functions), $m=3$ (number of functions) by Berenguer et al [14].

Example 3: Consider first kind Abel's integral equation of the form [13]

$$
\int_{0}^{x} \frac{1}{\sqrt{(x-t)}} u(t) d t=\frac{2}{105} \sqrt{x}\left(105-56 x^{2}+48 x^{3}\right) \quad 0 \leq x \leq 1
$$

The exact solution is $u(x)=x^{3}-x^{2}+1$. Results have been shown in Table 1 for $n=10$. The absolute errors are obtained in the order of $10^{-16}$ for Hermite polynomial basis. Also approximate solutions are same as exact solutions in the case of Chebyshev polynomials basis. On the other hand, the absolute errors were obtained in the order of $10^{-7}$ for $n=10$ (degree of Berstein's polynomials) by Maleknejad et al [13].

Example 4: Here we consider the first kind Abel integral equation [12] given by

$$
\int_{0}^{x} \frac{1}{\sqrt{(x-t)}} u(t) d t=x^{r}, 0 \leq x \leq 1
$$

where $r$ is any positive number. This is a first kind Volterra integral equation with weak singularity. The exact solution of the integral equation (17) is given by, 


$$
u(x)=\frac{2^{2 r-1}}{\pi} r \frac{(\Gamma r)^{2}}{\Gamma(2 r)} x^{r-\frac{1}{2}}
$$

In one numerical example $r$ is chosen as $r=5$ (integral value) while in another it is chosen as $\frac{3}{2}$ (non-integral value).

For $r=5$ the exact solution is $u(x)=\frac{1280}{315 \pi} x^{9 / 2}$. Numerical results with both polynomials have been shown in Table 2 for $n=10$. The absolute errors are obtained in the order of $10^{-8}$ for both polynomial basis while the absolute errors were obtained in the order of $10^{-7}$ for $n=10$ (degree of Berstein's polynomials) by Bhattacharya and Mandal [12].

For $r=\frac{3}{2}$ the exact solution is $u(x)=\frac{3}{4} x$. Using Hermite and Chebyshev polynomials and the formula derived in the equation (8) for $n \geq 1$, we get the approximate solution is $\tilde{u}(x)=\frac{3}{4} x$, which is the exact solution. On the contrary, the absolute errors were obtained in the order of $10^{-16}$ for $n=5$ (degree of Berstein's polynomials) by Bhattacharya and Mandal [12].

Table 1: Numerical results with analytical solutions of example 3 for $n=10$

\begin{tabular}{|c|c|c|c|c|c|}
\hline \multicolumn{6}{|c|}{ Example 3} \\
\hline \multirow[b]{2}{*}{$x$} & \multirow[b]{2}{*}{ Exact Solutions } & \multicolumn{2}{|c|}{ Hermite Polynomials Basis } & \multicolumn{2}{|c|}{ Chebyshev Polynomials Basis } \\
\hline & & $\begin{array}{l}\text { Approximate } \\
\text { Solutions }\end{array}$ & Absolute Error & $\begin{array}{c}\text { Approximate } \\
\text { Solutions }\end{array}$ & Absolute Error \\
\hline 0.0 & 1.000000000000000 & 1.000000000000000 & $0.0000000 \mathrm{E}+000$ & Same as exact & Coincide with the \\
\hline 0.1 & 0.990999999999999 & 0.990999999999999 & $0.0000000 \mathrm{E}+000$ & & exact solutions for \\
\hline 0.2 & 0.967999999999999 & 0.967999999999999 & $0.0000000 \mathrm{E}+000$ & ebyshev & using 4 pieces \\
\hline 0.3 & 0.936999999999999 & 0.936999999999999 & $0.0000000 \mathrm{E}+000$ & & Chebyshev \\
\hline 0.4 & 0.904000000000000 & 0.903999999999999 & $1.1102230 \mathrm{E}-016$ & & \\
\hline 0.5 & 0.875000000000000 & 0.875000000000000 & $0.0000000 \mathrm{E}+000$ & & \\
\hline 0.6 & 0.855999999999999 & 0.855999999999999 & $1.1102230 \mathrm{E}-016$ & & \\
\hline 0.7 & 0.852999999999999 & 0.852999999999999 & $0.0000000 \mathrm{E}+000$ & & \\
\hline 0.8 & 0.872000000000000 & 0.871999999999999 & 1.1102230E-016 & & \\
\hline 0.9 & 0.919000000000000 & 0.919000000000000 & $0.0000000 \mathrm{E}+000$ & & \\
\hline 1.0 & 1.000000000000000 & 1.000000000000000 & $0.0000000 \mathrm{E}+000$ & & \\
\hline
\end{tabular}

Example 5: Consider the second kind Abel's integral equation $[8,12]$ of the form

$$
u(x)-\int_{0}^{x} \frac{1}{\sqrt{(x-t)}} u(t) d t=x^{7}\left(1-\frac{4096}{6435} \sqrt{x}\right), 0 \leq x \leq 1
$$

The exact solution is $u(x)=x^{7}$. Numerical results are shown in Table 3 for $n=10$. The absolute errors are obtained in the order of $10^{-15}$ for Hermite polynomial basis. Also there is no error in the case of Chebyshev polynomials basis. On the other hand, the absolute errors were obtained in the order of $10^{-7}$ for $n=10$ (degree of Berstein's polynomials) by Bhattacharya and Mandal [12] and in [8] Shahsavaran reported the error upto $10^{-5}$ for $k=64$ (number of block pulse function). 
Table 2: Numerical results with analytical solutions of example 4 for $r=5$ and $n=10$

\begin{tabular}{|c|c|c|c|c|c|}
\hline \multicolumn{6}{|c|}{ Example 4 for $r=5$} \\
\hline \multirow[b]{2}{*}{$x$} & \multirow[b]{2}{*}{ Exact Solutions } & \multicolumn{2}{|c|}{ Hermite Polynomials Basis } & \multicolumn{2}{|c|}{ Chebyshev Polynomials Basis } \\
\hline & & $\begin{array}{l}\text { Approximate } \\
\text { Solutions }\end{array}$ & Absolute Error & $\begin{array}{c}\text { Approximate } \\
\text { Solutions }\end{array}$ & Absolute Error \\
\hline 0.0 & 0.000000000000000 & 0.000000130065256 & $1.3006526 \mathrm{E}-007$ & 0.000000130065245 & 1.3006525E-007 \\
\hline 0.1 & 0.000040902470789 & 0.000040923323991 & 2.0853202E-008 & 0.000040923323982 & 2.0853193E-008 \\
\hline 0.2 & 0.000925517262805 & 0.000925505766090 & $1.1496714 \mathrm{E}-008$ & 0.000925505766081 & $1.1496724 \mathrm{E}-008$ \\
\hline 0.3 & 0.005738457762588 & 0.005738474293789 & $1.6531200 \mathrm{E}-008$ & 0.005738474293786 & 1.6531197E-008 \\
\hline 0.4 & 0.020942065044315 & 0.020942045606297 & $1.9438018 \mathrm{E}-008$ & 0.020942045606303 & $1.9438012 \mathrm{E}-008$ \\
\hline 0.5 & 0.057162940708387 & 0.057162953563043 & $1.2854656 \mathrm{E}-008$ & 0.057162953563045 & $1.2854658 \mathrm{E}-008$ \\
\hline 0.6 & 0.129846476719332 & 0.129846477741079 & $1.0217471 \mathrm{E}-009$ & 0.129846477741060 & $1.0217281 \mathrm{E}-009$ \\
\hline 0.7 & 0.259830855487891 & 0.259830841672036 & $1.3815856 \mathrm{E}-008$ & 0.259830841672036 & $1.3815855 \mathrm{E}-008$ \\
\hline 0.8 & 0.473864838556323 & 0.473864859780821 & $2.1224498 \mathrm{E}-008$ & 0.473864859780843 & $2.1224520 \mathrm{E}-008$ \\
\hline 0.9 & 0.805083332553239 & 0.805083306075578 & $2.6477660 \mathrm{E}-008$ & 0.805083306075595 & $2.6477644 \mathrm{E}-008$ \\
\hline 1.0 & 1.293449696238895 & 1.293449495167074 & 2.0107182E-007 & 1.293449495167062 & 2.0107183E-007 \\
\hline
\end{tabular}

Table 3: Numerical results with analytical solutions of example 5 for $n=10$

\begin{tabular}{|c|c|c|c|c|c|}
\hline \multicolumn{6}{|c|}{ Example 5} \\
\hline \multirow[b]{2}{*}{$x$} & \multirow[b]{2}{*}{ Exact Solutions } & \multicolumn{2}{|c|}{ Hermite Polynomials Basis } & \multicolumn{2}{|c|}{ Chebyshev Polynomials Basis } \\
\hline & & $\begin{array}{l}\text { Approximate } \\
\text { Solutions }\end{array}$ & Absolute Error & $\begin{array}{l}\text { Approximate } \\
\text { Solutions }\end{array}$ & Absolute Error \\
\hline 0.0 & 0.000000000000000 & 0.000000000000000 & $0.0000000 \mathrm{E}+000$ & Same as exact & Coincide with the \\
\hline 0.1 & 0.000000100000000 & 0.000000099999998 & 1.0518363E-015 & & $\begin{array}{l}\text { exact solutions for } \\
n>7 \text { that means }\end{array}$ \\
\hline 0.2 & 0.000012800000000 & 0.000012799999999 & $5.2011042 \mathrm{E}-016$ & pieces Chebyshev & using 8 pieces \\
\hline 0.3 & 0.000218700000000 & 0.000218700000000 & $1.5883562 \mathrm{E}-017$ & & $\begin{array}{l}\text { Chebyshev } \\
\text { Polvnomials }\end{array}$ \\
\hline 0.4 & 0.001638400000000 & 0.001638399999997 & 2.1811979E-015 & & \\
\hline 0.5 & 0.007812500000000 & 0.007812500000000 & $0.0000000 \mathrm{E}+000$ & & \\
\hline 0.6 & 0.027993599999999 & 0.027993599999999 & $5.9674488 \mathrm{E}-016$ & & \\
\hline 0.7 & 0.082354299999999 & 0.082354300000000 & $2.4980018 \mathrm{E}-016$ & & \\
\hline 0.8 & 0.209715200000000 & 0.209715199999996 & 3.4694470E-015 & & \\
\hline 0.9 & 0.478296900000000 & 0.478296899999995 & 4.1633363E-015 & & \\
\hline 1.0 & 1.000000000000000 & 1.000000000000003 & 3.5527137E-015 & & \\
\hline
\end{tabular}

Example 6: Consider the second kind Abel's integral equation [5]

$$
u(x)+\int_{0}^{x} \frac{1}{\sqrt{(x-t)}} u(t) d t=x^{2}+\frac{16}{15} x^{\frac{5}{2}}, 0 \leq x \leq 1
$$

The exact solution is $u(x)=x^{2}$. Using Hermite and Chebyshev polynomials and the formula derived in the equation (11) for $n \geq 2$, we get the approximate solution is $\tilde{u}(x)=x^{2}$, which is the exact solution. On the other hand, the absolute errors were obtained in the order of $10^{-3}$ for $k=32$ (number of block-pulse functions) by Shahsavaran [5]. 
Example 7: Consider the nonlinear Volterra integral equation [15]

$$
u(x)-0.25 \int_{0}^{x}(x-t) u^{2}(t) d t=2 x-\frac{1}{12} x^{4}, 0 \leq x \leq 1
$$

The exact solution is $u(x)=2 x$. We approximate $u(x)$ as

$$
\tilde{u}(x)=\sum_{i=0}^{n} c_{i} N_{i}(x)
$$

where $N_{i}(x)$ are Hermite or Chebyshev polynomials of degree $i$. Using (21) into Eqn. (20), the Galerkin weighted residual equations are:

$$
\int_{0}^{1}\left[\tilde{u}(x)-0.25 \int_{0}^{x}(x-t) \tilde{u}^{2}(t) d t-2 x+\frac{1}{12} x^{4}\right] N_{j}(x)=0 ; j=1,2,3, \ldots, n
$$

Using the method discussed in section 3 and with minor simplifications, the above equations (22) are equivalent to

$$
D C=B
$$

where the elements of the matrix $C, D$ and $B$ are $c_{i}, d_{i, j}$ and $b_{j}$, respectively, given by

$$
\begin{aligned}
& c_{i}=\left[c_{1}, c_{2}, c_{3}, \ldots \ldots \ldots \ldots c_{n}\right]^{T} \\
& d_{i, j}=\left[\int _ { 0 } ^ { 1 } \left[N_{i}(x)-\underset{a}{\left.\left.0.25 \int_{k=1}^{x}(x-t) \sum_{k}^{n} c_{k} N_{k}(t) N_{i}(t) d t\right] N_{j}(x) d x\right], i, j=1, \ldots \ldots, n}\right.\right. \\
& b_{j}=\int_{0}^{1}\left(2 x-\frac{1}{12} x^{4}\right) N_{j}(x) d x, j=1, \ldots \ldots, n
\end{aligned}
$$

Now the initial values of the coefficients $c_{i}$ are obtained by applying the modified Galerkin method to the Volterra integral equation (20) converting it to linear. That is to find initial coefficients we will solve the system only

$$
D C=B
$$

where the elements of the matrix $C, D$ and $B$ are $c_{i}, d_{i, j}$ and $b_{j}$, respectively, given by

$$
\begin{aligned}
& c_{i}=\left[c_{1}, c_{2}, c_{3}, \ldots \ldots \ldots \ldots c_{n}\right]^{T} \\
& d_{i, j}=\left[\int _ { 0 } ^ { 1 } \left[N_{i}(x)-\underset{a}{\left.\left.0.25 \int_{a}^{x}(x-t) N_{i}(t) d t\right] N_{j}(x) d x\right], i, j=1, \ldots \ldots, n}\right.\right. \\
& b_{j}=\int_{0}^{1}\left(2 x-\frac{1}{12} x^{4}\right) N_{j}(x) d x, j=1, \ldots \ldots, n
\end{aligned}
$$

Once the initial values of the $c_{i}$ are obtained from Eqn. (24), they are substituted into Eqn. (23) to obtain new estimates for the values of $c_{i}$. This iteration process continues until the converged values of the unknown parameters are obtained. Substituting the final values of the parameters in Eqn. (21), we obtain the approximate solutions of the integral equations (20). Numerical results are shown in Table 4.

Example 8: Consider the nonlinear Volterra integral equation [2, 15]

$$
u(x)+\int_{0}^{x} t u^{3}(t) d t=x+\frac{1}{5} x^{5}, 0 \leq x \leq 1
$$


The exact solution is $u(x)=x$. Approximate results and analytical solutions are given in Table 5 .

Table 4: Numerical results for nonlinear problem in example 7.

\begin{tabular}{|c|c|c|c|c|c|c|c|}
\hline \multicolumn{2}{|c|}{$\mathrm{n}=5$, Iteration $=8$} & \multicolumn{2}{|c|}{ Hermite Polynomials Basis } & \multicolumn{2}{|c|}{ Chebyshev Polynomials Basis } & \multicolumn{2}{|c|}{$\begin{array}{l}\text { Method in [15], } \\
\mathrm{h}=0.1, \mathrm{n}=10\end{array}$} \\
\hline$x$ & $\begin{array}{l}\text { Exact } \\
\text { Solutions }\end{array}$ & $\begin{array}{l}\text { Approximate } \\
\text { Solutions }\end{array}$ & Absolute Error & $\begin{array}{l}\text { Approximate } \\
\text { Solutions }\end{array}$ & Absolute Error & $\begin{array}{l}\text { Approx. } \\
\text { Solutions }\end{array}$ & $\begin{array}{l}\text { Absolute } \\
\text { Error }\end{array}$ \\
\hline 0.0 & 0.0000000000 & 4.730367E-014 & $4.730367 \mathrm{E}-014$ & 7.990960E-016 & 7.990960E-016 & 0.0000 & 00000000 \\
\hline 0.1 & 0.2000000000 & 0.2000000000 & $7.827072 \mathrm{E}-015$ & 0.2000000000 & $1.110223 \mathrm{E}-016$ & 0.2000 & 00000000 \\
\hline 0.2 & 0.4000000000 & 0.4000000000 & $2.026157 \mathrm{E}-014$ & 0.4000000000 & $3.885781 \mathrm{E}-016$ & 0.4000 & 00000000 \\
\hline 0.3 & 0.6000000000 & 0.6000000000 & 8.437695E-015 & 0.6000000000 & 3.330669E-016 & 0.5999 & $1.00 \mathrm{E}-004$ \\
\hline 0.4 & 0.8000000000 & 0.8000000000 & $9.658940 \mathrm{E}-015$ & 0.8000000000 & $1.110223 \mathrm{E}-016$ & 0.7999 & $1.00 \mathrm{E}-004$ \\
\hline 0.5 & 1.0000000000 & 1.0000000000 & 1.976197E-014 & 1.0000000000 & $2.220446 \mathrm{E}-016$ & 0.9998 & 2.00E-004 \\
\hline 0.6 & 1.2000000000 & 1.2000000000 & $1.465494 \mathrm{E}-014$ & 1.2000000000 & 0.00000000000 & 1.1997 & $3.00 \mathrm{E}-004$ \\
\hline 0.7 & 1.4000000000 & 1.4000000000 & 4.662937E-015 & 1.4000000000 & 0.00000000000 & 1.3995 & 5.00E-004 \\
\hline 0.8 & 1.6000000000 & 1.6000000000 & $2.464695 \mathrm{E}-014$ & 1.6000000000 & $2.220446 \mathrm{E}-016$ & 1.5993 & 7.00E-004 \\
\hline 0.9 & 1.8000000000 & 1.8000000000 & $1.532108 \mathrm{E}-014$ & 1.8000000000 & $2.220446 \mathrm{E}-016$ & 1.7991 & $9.00 \mathrm{E}-004$ \\
\hline
\end{tabular}

Table 5: Numerical results for nonlinear problem in example 8.

\begin{tabular}{|c|c|c|c|c|c|c|c|}
\hline \multicolumn{8}{|c|}{ Example 8: } \\
\hline \multicolumn{2}{|c|}{$\mathrm{n}=7$, Iteration $=15$} & \multicolumn{2}{|c|}{ Hermite Polynomials Basis } & \multicolumn{2}{|c|}{ Chebyshev Polynomials Basis } & \multicolumn{2}{|c|}{$\begin{array}{l}\text { Method in [15], } \\
h=0.1, n=10\end{array}$} \\
\hline$x$ & $\begin{array}{l}\text { Exact } \\
\text { Solutions }\end{array}$ & $\begin{array}{l}\text { Approximate } \\
\text { Solutions }\end{array}$ & Absolute Error & $\begin{array}{l}\text { Approximate } \\
\text { Solutions }\end{array}$ & Absolute Error & $\begin{array}{l}\text { Approx. } \\
\text { Solutions }\end{array}$ & $\begin{array}{l}\text { Absolute } \\
\text { Error }\end{array}$ \\
\hline 0.0 & 0.0000000000 & $-3.23667 \mathrm{E}-012$ & $3.236672 \mathrm{E}-012$ & $-6.79107 \mathrm{E}-014$ & 6.791065E-014 & 0.0000 & 00000000 \\
\hline 0.1 & 0.1000000000 & 0.1000000000 & 1.308995E-012 & 0.1000000000 & 3.153033E-014 & 0.1000 & 00000000 \\
\hline 0.2 & 0.2000000000 & 0.2000000000 & $2.685074 \mathrm{E}-013$ & 0.2000000000 & 8.992806E-015 & 0.2001 & $1.00 \mathrm{E}-004$ \\
\hline 0.3 & 0.3000000000 & 0.3000000000 & $1.004197 \mathrm{E}-012$ & 0.3000000000 & $2.836620 \mathrm{E}-014$ & 0.3003 & 3.00E-004 \\
\hline 0.4 & 0.4000000000 & 0.4000000000 & 4.030110E-014 & 0.4000000000 & 2.109424E-015 & 0.4011 & $1.10 \mathrm{E}-003$ \\
\hline 0.5 & 0.5000000000 & 0.5000000000 & 8.981704E-013 & 0.5000000000 & $2.620126 \mathrm{E}-014$ & 0.5027 & $2.70 \mathrm{E}-003$ \\
\hline 0.6 & 0.6000000000 & 0.6000000000 & 4.498624E-013 & 0.6000000000 & 1.687439E-014 & 0.6056 & $5.60 \mathrm{E}-003$ \\
\hline 0.7 & 0.7000000000 & 0.7000000000 & 7.689405E-013 & 0.7000000000 & $1.898481 \mathrm{E}-014$ & 0.7104 & 1.04E-002 \\
\hline 0.8 & 0.8000000000 & 0.8000000000 & $6.270540 \mathrm{E}-013$ & 0.8000000000 & $2.253753 E-014$ & 0.8172 & $1.72 \mathrm{E}-002$ \\
\hline 0.9 & 0.9000000000 & 0.9000000000 & $1.226685 \mathrm{E}-012$ & 0.9000000000 & $2.775558 \mathrm{E}-014$ & 0.9261 & 2.61E-002 \\
\hline
\end{tabular}

Example 9: Consider the nonlinear Volterra integral equation $[2,6,7,16]$

$$
u(x)-0.5 \int_{0}^{x} u^{2}(t) d t=\sin x+\frac{1}{8} \sin 2 x-\frac{1}{4} x, 0 \leq x \leq 1
$$

The exact solution is $u(x)=\sin x$. The computational results together with the exact solutions are summarized in Table 6. 
Table 6: Numerical results for nonlinear problem in example 9

\begin{tabular}{c|l|l|l|l|l|l|l|l|l|l}
\hline \multicolumn{2}{l}{$\mathbf{n = 8 ,}$ Iteration=5 } & \multicolumn{2}{l}{ Hermite Polynomials Basis } & \multicolumn{2}{l}{$\begin{array}{l}\text { Chebyshev Polynomials } \\
\text { Basis }\end{array}$} & \multicolumn{2}{l}{$\begin{array}{l}\text { Method in [6,7], } \\
\text { k=16 }\end{array}$} & \multicolumn{2}{l}{$\begin{array}{l}\text { Method in [16], } \\
\mathbf{m = 6 4}\end{array}$} \\
\hline$x$ & $\begin{array}{l}\text { Exact } \\
\text { Solutions }\end{array}$ & $\begin{array}{l}\text { Approxima } \\
\text { tion }\end{array}$ & Absolute Error & $\begin{array}{l}\text { Approxima } \\
\text { tion }\end{array}$ & $\begin{array}{l}\text { Absolute Error } \\
\text { Approxi }\end{array}$ & $\begin{array}{l}\text { Absolute } \\
\text { mate } \\
\text { Error }\end{array}$ & $\begin{array}{l}\text { Approxim } \\
\text { ate }\end{array}$ & $\begin{array}{l}\text { Absolute } \\
\text { Error }\end{array}$ \\
\hline 0.1 & 0.09983342 & 0.09983340 & $1.268904 \mathrm{E}-008$ & 0.09983349 & $7.237896 \mathrm{E}-008$ & 0.0936 & $6.20 \mathrm{E}-003$ & 0.101388 & $1.555 \mathrm{E}-003$ \\
0.2 & 0.19866933 & 0.19866934 & $1.359706 \mathrm{E}-008$ & 0.19866926 & $6.891281 \mathrm{E}-008$ & 0.2070 & $8.30 \mathrm{E}-003$ & 0.194073 & $4.596 \mathrm{E}-003$ \\
0.3 & 0.29552021 & 0.29552021 & $2.772627 \mathrm{E}-009$ & 0.29552018 & $2.279002 \mathrm{E}-008$ & 0.2776 & $1.79 \mathrm{E}-002$ & 0.299995 & $4.475 \mathrm{E}-003$ \\
0.4 & 0.38941834 & 0.38941831 & $1.271718 \mathrm{E}-008$ & 0.38941841 & $6.558225 \mathrm{E}-008$ & 0.3952 & $5.80 \mathrm{E}-003$ & 0.387978 & $1.440 \mathrm{E}-003$ \\
0.5 & 0.47942554 & 0.47942551 & $3.413828 \mathrm{E}-009$ & 0.47942556 & $2.553201 \mathrm{E}-008$ & 0.5067 & $2.73 \mathrm{E}-002$ & 0.486266 & $6.840 \mathrm{E}-003$ \\
0.6 & 0.56464247 & 0.56464249 & $1.274871 \mathrm{E}-008$ & 0.56464241 & $6.199959 \mathrm{E}-008$ & 0.5596 & $5.00 \mathrm{E}-003$ & 0.565930 & $1.288 \mathrm{E}-003$ \\
0.7 & 0.64421769 & 0.64421769 & $7.146748 \mathrm{E}-009$ & 0.64421766 & $2.294463 \mathrm{E}-008$ & 0.6514 & $7.20 \mathrm{E}-003$ & 0.640624 & $3.594 \mathrm{E}-003$ \\
0.8 & 0.71735609 & 0.71735609 & $1.076512 \mathrm{E}-009$ & 0.71735619 & $8.890549 \mathrm{E}-008$ & 0.7243 & $6.90 \mathrm{E}-003$ & 0.720611 & $3.255 \mathrm{E}-003$ \\
0.9 & 0.78332691 & 0.78332697 & $6.461735 \mathrm{E}-008$ & 0.78332693 & $1.665020 \mathrm{E}-008$ & 0.7874 & $4.10 \mathrm{E}-003$ & 0.782351 & $9.760 \mathrm{E}-004$ \\
\hline
\end{tabular}

\section{CONCLUSIONS}

We have obtained the approximation solutions of linear and nonlinear Volterra integral equations using Hermite and Chebyshev polynomials as trial function in the basis by the technique of Galerkin method. The proposed method has been applied to solve several number of Volterra integral equations both second and first kind with regular as well as weakly singular kernels. The numerical results obtained by the proposed method are in good agreement with the exact solutions. Observe that the numerical solutions coincide with the exact solutions even a lower degree both polynomials are used in the approximation. Also we notice that the both polynomials provide us the smaller absolute error than the absolute error obtained in $[5-8,12-16]$, and the Chebyshev polynomials gives the best solutions than the Hermite polynomials, which are shown in Table [1-6]. The author's concluding remark is that this technique may be applied to other integral equations to get the desired and reliable good accuracy.

\section{REFERENCES}

[1] Jerri, Abdul J. 1999. Introduction to Integral Equations with Applications, John Wiley \& Sons Inc.

[2] Rahman, M. 2007. Integral equations and their applications, WIT Press.

[3] Bellour Azzeddine and Rawashdeh E. A., 2010. Numerical solution of first kind integral Equations by using Taylor polynomials, J. Inequal. Speci. Func., Vol.1, Issue 2, 23-29.

[4] Maleknejad, K., Roodaki M. and Almasieh, H., 2009. Numerical Solution of Volterra Integral Equations of First Kind by Using a Recursive Scheme, J. Mathe. Extens., Vol. 3, 113 - 121.

[5] Shahsavaran, A. 2011. Numerical Approach to Solve Second Kind Volterra Integral Equations of Abel Type Using Block - Pulse Functions and Taylor Expansion by Collocation Method, Appl. Mathe. Sci., Vol. 5, 685 - 696.

[6] Shahsavaran, Ahmad. 2011. Numerical Solution of Nonlinear Fredholm-Volterra Integral Equations via Piecewise Constant Function by Collocation Method, American Journal of Computational Mathematics, 1, 134-138. doi:10.4236/ajcm.2011.12014.

[7] Shahsavaran, Ahmad. 2011. Computational Method to Solve Nonlinear Integral Equations Using Block Pulse Functions by Collocation Method, Appl. Mathe. Sci., 5, 3211 - 3220.

[8] Shahsavaran, A. 2011. Haar Wavelet Method to Solve Volterra Integral Equations with Weakly Singular Kernel by Collocation Method, Appl. Mathe. Sci., Vol. 5 , 3201 - 3210.

[9] Chen Yanping and Tang, Tao. 2009. Spectral methods for weakly singular Volterra integral equations with smooth solutions, J. Comput. Appl. Math., 233, 938 - 950. doi:10.1016/j.cam.2009.08.057.

[10] Maleknejad, K., Sohrabi S. and Rostami, Y. 2007. Numerical solution of nonlinear Volterra integral equations of second kind by using Chebyshev polynomials, Appl. Math. Comput. 188, 123 - 128. 
[11] Jafari, H., Hosseinzadeh, H. and Mohamadzadeh, S. 2010. Numerical Solution of System of Linear Integral Equations by using Legendre Wavelets, Int. J. Open Problems Compt. Math., 3, 63- 71.

[12] Bhattacharya, Subhra and Mandal, B. N. , 2008. Use of Bernstein polynomials in Numerical Solutions of Volterra Integral Equations, Appl. Mathe. Sci., 2, $1773-1787$.

[13] Maleknejad, K., Hashemizadeh, E. and Ezzati, R. 2011. A new approach to the Numerical solution of Volterra integral equations by using Bernstein's approximation, Commun. Nonlinear Sci. Numer. Simulat., 16, 647-655. doi: 10.1016/j.cnsns.2010.05.006

[14] Berenguer, M. I., Ga'mes, D. and Garralda-Guillem, A. I., Ruiz Ga'lan, M. and Serrano Pe'rez, M. C. 2009. Analytical Techniques for a Numerical Solution of the Linear Volterra Integral Equation of the Second Kind, Abstract and Applied Analysis, Volume 2009, Article ID 149367, 12 pages. doi:10.1155/2009/149367

[15] Kamyad, A. V., Mehrabinezhad, M. and Saberi-Nadjafi, J. , 2010. A Numerical Approach for Solving Linear and Nonlinear Volterra Integral Equations with Controlled Error, IAENG International Journal of Applied Mathematics, 40, $71-76$.

[16] Babolian, E., Masouri, Z. and Hatamzadeh-Varmazyar, S. 2008. New Direct Method To Solve Nonlinear VolterraFredholm Integral and Integro-Differential Equations Using Operational Matrix With Block-Pulse Functions, Progress In Electromagnetics Research B, 8, 59 - 76.

[17] Saran, N., Sharma, S. D. and Trivedi, T. N. 2000. Special Functions, Seventh edition, Pragati Prakashan.

[18] Lewis, P. E. and Ward, J. P. 1991. The Finite Element Method, Principles and Applications, Addison-Wesley.

\section{AUTHOR'S BIOGRAPHY}

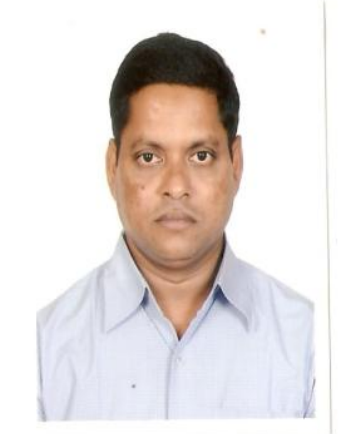

Md. Shafiqul Islam received his B.Sc. Honors from Dhaka University in 1991, M.Sc. from Dhaka University in 1993, and Ph.D. degree from Bangalore University in 2002. He has been working as Professor of Mathematics, University of Dhaka since 2010. His research interest includes Numerical Integration, Finite Element Method, Numerical solutions of ODE, PDE and Integral Equations. He is a Member of American Mathematical Society (AMS), USA and, Society for Industrial and Applied Mathematics (SIAM), USA, He was Secretary of Bangladesh Mathematical Society, 2010 - 2011, Bangladesh.
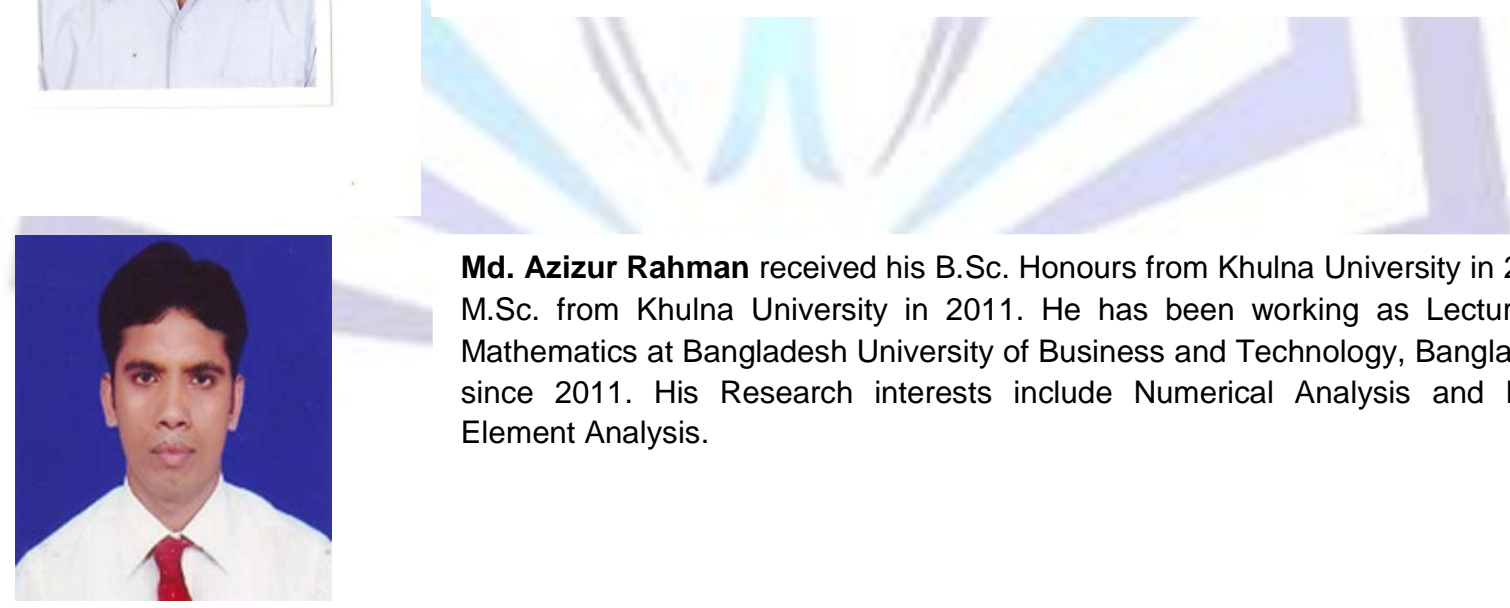

Md. Azizur Rahman received his B.Sc. Honours from Khulna University in 2008, M.Sc. from Khulna University in 2011. He has been working as Lecturer in Mathematics at Bangladesh University of Business and Technology, Bangladesh since 2011. His Research interests include Numerical Analysis and Finite Element Analysis. 